\title{
Association between metabolic indicators and clinical endometritis during the transition period in Brown Swiss cows*
}

\author{
MURAT ONUR YAZLIK ${ }^{1}$, HATICE ESRA COLAKOGLU1, MERT PEKCAN ${ }^{2}$, UFUK KAYA ${ }^{3}$, \\ SERDAL KURT ${ }^{4}$, SUKRU KUPLULU1 ${ }^{1}$, CIHAN KACAR ${ }^{5}$, RIFAT VURAL ${ }^{1}$
}

\begin{abstract}
1'Department of Obstetrics and Gyneacology, Faculty of Veterinary Medicine, Ankara University, Ankara, 06110, Turkey ${ }^{2}$ Department of Biochemistry, Faculty of Veterinary Medicine, Ankara University, Ankara, 06110, Turkey

${ }^{3}$ Department of Biostatistics, Faculty of Veterinary Medicine, Mustafa Kemal University, Hatay, Turkey ${ }^{4}$ Department of Obstetrics and Gyneacology, Faculty of Veterinary Medicine, Dicle University, Diyarbakır, Turkey

${ }^{5}$ Department of Obstetrics and Gyneacology, Faculty of Veterinary Medicine, Kafkas University, Kars, Turkey
\end{abstract}

\section{Yazlik M. O., Colakoglu H. E., Pekcan M., Kaya U., Kurt S., Kuplulu S., Kacar C., Vural R. \\ Association between metabolic indicators and clinical endometritis during the transition period in Brown Swiss cows}

\section{Summary}

The objective of the current study was to evaluate the relationship between the serum macromineral, metabolite profiles, and the clinical endometritis during the transition period in Brown Swiss dairy cows. Sixty Brown Swiss dairy cows were used in the present study. Blood samples collected at $d 10( \pm 4)$ antepartum and 3 , 10 and $30( \pm 4)$ days in milk (DIM) to determine calcium (Ca), phosphorus, glucose, cholesterol, non-esterified fatty acid (NEFA) levels. Beta-hydroxybutyric acid (BHB) concentration measured during the postpartum period. Receiver operating characteristics (ROC) curves were used to determine the cow-level thresholds for the subsequent development of clinical endometritis. In addition, pairwise comparisons were made of the area under the curve (AUC) of ROC curves for the thresholds of NEFA, Ca, and glucose predicting clinical endometritis. The mean Ca concentration at $3 \mathrm{DIM}$ was $8.85 \pm 0.20 \mathrm{mg} / \mathrm{dL}$ in healthy cows compared to $8.30 \pm 0.22 \mathrm{mg} / \mathrm{dL}$ in cows that subsequently developed endometritis $(\mathrm{P}<0.05)$. NEFA concentrations at $10 \mathrm{DIM}$ and $\mathrm{BHB}$ concentration at 10 and $30 \pm 4 \mathrm{DIM}$ were higher $(\mathrm{P}<0.05)$ in cows that subsequently developed endometritis. Serum NEFA concentration at $\mathbf{1 0}$ days postpartum is the best predictor for diagnosis of clinical endometritis with the AUC values of 0.741 . The cows with clinical endometritis also had significantly higher values of glucose at 3 DIM and lower BCS at 10 DIM $(\mathrm{P}<0.05)$. While $58.6 \%$ of the cows that developed clinical endometritis were cyclic, $64.5 \%$ were cyclic in healthy cows at $30 \pm 4$ DIM. Serum NEFA concentration was the only risk factor for clinical endometritis at 10 DIM. In addition, a decrease in serum Ca at 3 DIM and increase in NEFA and BHB concentrations at 10 and $30 \pm 4$ DIM may be associated with clinical endometritis and delayed resumption activity on the ovaries.

Keywords: Brown Swiss, clinical endometritis, metabolic profile

The peripartum period is characterized by systemic changes that directly influence the postpartum period. Changes in dry matter intake during the transition period are one of the important factors that affect postpartum health, productivity, and fertility of dairy cows (15). Previous studies have shown that a decrease in

* This work was supported by the Ankara University Scientific Research Projects Coordination Unit. A preliminary version of this study was presented at the $27^{\text {th }}$ International Scientific Conference in Stara Zagora, Bulgaria, 2017 Comparison of Serum Macromineral Concentrations and Metabolite Profiles in Brown Swiss Cows That Healthy and Developed Clinical Endometritis, Congress Proceedings, pp. 122. feed consumption during the prepartum period is a predisposing factor for suppression of immune response and greater susceptibility to genital tract infections $(16,17)$. Dairy cows mobilize body reserves during the transition period if an energy deficit exists due to the imbalance between energy intake and requirements. However, the degree of fat mobilization varies for each cow (23). The characterization of a dairy cow's negative energy balance is mobilizing fat from the body stores, as non-esterified fatty acid (NEFA), to utilize energy. Beta-hydroxybutyric acid (BHB) is another 
important metabolite which helps to monitor postpartum energy metabolism as well as the immune function (16). In herd level monitoring the NEFA concentration during the prepartum period provides an advantage for predicting postpartum events. Moreover, BHB is strongly associated with periparturient disorders and increased culling rates $(7,12,25,36)$.

There are major changes in the mechanism of calcium $(\mathrm{Ca})$ homeostasis to produce milk at the beginning of lactation. During the dry period, the main input of $\mathrm{Ca}$ is gastrointestinal absorption, but at the beginning of lactation bone resorption increases and excretion from feces decreases (35). Adaptation to Ca deficiency at the beginning of lactation is not rapid enough; cows need at least 1 to 2 days to adapt to $\mathrm{Ca}$ inflow. Therefore, almost all cows experience some degree of calcium deficiency during the begining of lactation. While the incidence of clinical hypocalcemia is 5\%, almost $50 \%$ of cows suffer from subclinical hypocalcemia during the periparturient period (29). However, total plasma $\mathrm{Ca}$ concentration returns to normal levels within 2 to 3 days $(17,34)$. Decreased Ca concentration impairs leukocyte activity, increases the rate of uterine infection and decreases reproductive performance in dairy cows (27).

One of the most common subfertility and infertility problems in dairy cows is clinical endometritis that is characterized by a purulent discharge originating from the uterus (38). The association of subclinical hypocalcemia, lipid metabolism, and the health of dairy cows has been given less attention during the past decade. Martinez et al. (26) reported that cows with subclinical hypocalcemia were at greater risk of developing metritis and endometritis. However, Chapinal et al. (7) refuted that finding and reported that hypocalcemia is associated with displaced abomasum. Although the relationship between serum metabolites and fertility parameters have been reported earlier (33), the exact role of energy markers and ions on clinical endometritis has not been described.

The hypothesis of the current study was that the $\mathrm{Ca}$, phosphorus (P), glucose, cholesterol, NEFA and BHB levels, and body condition score (BCS) are associated with the occurence of clinical endometritis. Changes in these parameters would help to determine susceptible animals for clinical endometritis before the clinical signs exist during the transition period. The objective of the current study was to clarify the relationship and corrrelation among concentrations of ions $(\mathrm{Ca}, \mathrm{P})$ and metabolites (NEFA, BHB, glucose and cholesterol) in cows with and without clinical endometritis at $30 \pm 4$ days in milk (DIM).

\section{Material and methods}

Animals, housing and diets. A total of 68 Brown Swiss dairy cows between 2 to 3 lactations from a commercial dairy herd in Turkey used in present study. The average lactation milk yield of animals was $6000 \mathrm{~kg}$. The Brown
Tab. 1. Integrant of diets fed during far-off $(-50$ to $-31 \mathrm{~d}$ relative to expected calving), close-up ( $-30 \mathrm{~d}$ to calving), and early lactation

\begin{tabular}{|c|c|c|c|}
\hline Component & Far-off & Close-up & Early lactation \\
\hline \multicolumn{4}{|l|}{ Ingredient, $\%$ of DM } \\
\hline Vetch hay & 11.58 & - & - \\
\hline Alfalfa silage & - & - & 9.67 \\
\hline Alfalfa hay & 7.89 & 6.97 & 10.29 \\
\hline Corn silage & 52.60 & 43.51 & 44.16 \\
\hline Wheat straw & 10.52 & 22.25 & - \\
\hline Soybean meal, $48 \%$ CP & - & - & 1.61 \\
\hline Concentrated feed & 15.78 & 20.94 & 30.31 \\
\hline Limestone & 0.82 & 2.25 & 1.57 \\
\hline Salt & 0.30 & - & 0.26 \\
\hline Ammonium chloride & - & 1.15 & - \\
\hline Dicalcium phosphate & 0.14 & 0.30 & 0.44 \\
\hline Magnesium oxide & - & 0.12 & 0.44 \\
\hline Magnesium sulphate & 0.16 & 1.35 & 0.25 \\
\hline Sodium bicarbonate & - & - & 0.7 \\
\hline Calcium sulphate & - & - & 0.1 \\
\hline Mineral-vitamin mix* & 0.21 & 0.17 & 0.2 \\
\hline
\end{tabular}

Explanations: *contained a minimum of $4.3 \% \mathrm{Mg}, 8 \% \mathrm{~S}, 6.1 \% \mathrm{~K}$, $2.0 \% \mathrm{Fe}, 3.0 \% \mathrm{Zn}, 3.0 \% \mathrm{Mn}, 5000 \mathrm{mg} / \mathrm{kg} \mathrm{Cu}, 250 \mathrm{mg} / \mathrm{kg}$ of I, $40 \mathrm{mg} / \mathrm{kg}$ of Co, $150 \mathrm{mg} / \mathrm{kg} \mathrm{Se}, 2200 \mathrm{kIU} / \mathrm{kg}$ of vitamin A, $660 \mathrm{kIU} / \mathrm{kg}$ of vitamin $\mathrm{D}_{3}$, and $7700 \mathrm{IU} / \mathrm{kg}$ of vitamin $\mathrm{E}$

Swiss dairy cows milked two times and milk yields recorded daily in a double 48-stall parallel milking parlor. Moreover, they were housed in freestall resting barns that had artificial lighting and natural ventilation. Cows were fed for $a d$ libitum intake twice daily with a total mixed ration (TMR). The composition of TMR that was offered during the study period is shown in Table 1. TMR offered thrice daily with equally split between feedings and was prepared by vertical mixer feeder.

Study design. Animals were enrolled in the study at 10 $( \pm 4)$ days prior to expected parturition date. Animals were divided into two groups at $30( \pm 4)$ DIM as cows that subsequently developed clinical endometritis $(\mathrm{n}=29)$ and healthy cows $(n=31)$ according to gynecological examinations. Their disease status in the postpartum period and blood ion and metabolite concentrations were analyzed. None of the cows received any product containing supplemental $\mathrm{Ca}$ or gluconeogenic precursors, or any antimicrobial therapy for prophylaxis. The rectal temperature of cows was measured and recorded daily during the first 10 DIM using an electronic thermometer just after milking and vaginal discharge were evaluated during the same period for diagnosing metritis. The occurrence of any problem like dystocia or diseases such as clinical ketosis, metritis, and retained placenta during first 10 DIM were recorded in DairyPlan $\left(\mathrm{Gea}^{\circledR}\right)$ for retreival at end of the study period.

Serum concentrations of Ca, P, NEFA, BHB, glucose and cholesterol. Blood sampling was performed at $10( \pm 4)$ days prepartum, 3, 10 and $30( \pm 4)$ DIM. The coccygeal artery or vein were choosen for the collection of blood 
samples. Samples were taken into evacuated tubes without anticoagulant. Then samples were clotted and then placed on ice until processing. Blood samples were centrifuged within 1 hour of collection, after that serum transferred to another tube and frozen at $-20^{\circ} \mathrm{C}$ until analysis. Total $\mathrm{Ca}, \mathrm{P}$, glucose, cholesterol and NEFA concentrations were identified in all sampling days. However, serum BHB concentration were measured on postpartum sampling days. Serum samples were analyzed for concentrations of cholesterol, glucose, $\mathrm{P}$ and $\mathrm{Ca}$ by using an autoanalyzer (ERBA XL $600^{\circledR}$ ). Commercial NEFA (NEFA-C Kit; Wako Diagnostics Inc.) and BHB (Wako Autokit 3-HB; Wako Diagnostic Inc.) kits were used for determination of levels by using same device. Serum calcium limit for determination of subclinical hypocalcemia was determined as $\leq 8.6 \mathrm{mg} / \mathrm{dl}(15)$. Also, energy balance was assessed by using measurements of glucose, NEFA, and BHB as described previously $(28,31)$. Metabolite concentrations as follows: NEFA $\geq 0.3 \mathrm{mEq} / \mathrm{L}$, $\mathrm{NEFA} \geq 0.7 \mathrm{mEq} / \mathrm{L}$, prepartum and postpartum respectively and $\mathrm{BHB} \geq 1.000 \mathrm{mmol} / \mathrm{L}$ postpartum.

Ovarian cyclicity and clinical endometritis. Resumption of ovarian cyclicity at postpartum period was evaluated at $30( \pm 4)$ DIM by transrectal ultrasonography (SIUI CTS $800^{\circledR}$, equipped with 6.5-9.5 MHz linear prob). Cows with at least one corpus luteum recorded on this day were considered to be cyclic, whereas in the absence of the corpus luteum animals with incidental follicles smaller than $9 \mathrm{~mm}$ in diameter were considered anovulatory. On the same day of reproductive tract examination, vaginal discharge score was evaluated based on a scoring system as previously described. The scoring scale was: 0 for a clear or translucent mucus, 1 for a mucus containing flecks of white or off-white pus, 2 for containing $\leq 50 \%$ white or off-white mucopurulent material and 3 for a discharge containing $>50 \%$ purulent material and $\geq 1$ was diagnosed as clinical endometritis (40).

BCS and milk yield. Body condition scores were determined using 5-point scale in 0.25-unit increments as described previously (13) on the days of blood sampling. Milk yield was also recorded during the study period.

Environment data. The temperature of barns together with humidity was recorded daily for evaluation of temperature humidity index (THI). Daily maximum and minimum temperature and THI, were calculated as described (1). THI above 72 was indicative of heat stress.

Statistical analysis. This was an observational cohort experiment. Cows were enrolled in weekly cohorts of 5 to 7 animals. Descriptive statistics for each variable were calculated and presented as "mean \pm standart error of mean." The correlation among metabolites and ions were evaluated. The Pearson correlation coefficient was used to determine the correlation between BCS, concentration of NEFA, BHB, $\mathrm{Ca}, \mathrm{P}$ and glucose for each sampling period. Correlation coefficients were considered as Strong, Moderate, and Weak when $r>0.5, r=0.31-0.5$, and $r<0.3$, respectively. Linear mixed models were applied to estimate group, day of sampling and their interaction effects. The effect of group, day of sampling and their interaction on BCS, concentrations of NEFA, BHB, Ca, P and glucose were analyzed using the following model with repeated measures:

$$
Y_{i j k}=\mu+G_{i}+D_{j}+(G \times D)_{i j}+e_{i j k}
$$

where: $Y_{i j k}$ is the dependent variable; $\mu$ is the overall mean; $G_{i}$ is the effect of the group ( $i=$ Healthy cows and cows that subsequently developed clinical endometritis); $D_{j}$ is the effect of day of sampling $(j=-10( \pm 4), 3,10$ and $30( \pm 4)$ days); $(G \times D)_{i j}$ is the interaction between group $i$ and day of sampling $j$; and $e_{i j k}$ is the residual error.

Animals within a group were assessed as a random effect, while group, day of sampling and their interaction were assessed as a fixed effect. When a significant difference was revealed, any significant terms were compared by Simple effect analysis with Bonferroni adjustment. Significance was declared $\mathrm{P}<0.05$ in all analyses. IBM SPSS 23 (Armonk, NY, USA) was used for analysis of the data.

Receiver operating characteristic (ROC) curves were obtained using MedCalc version 9.2.0.1. The concentrations of NEFA, BHB, Ca and glucose were evaluated with ROC analysis to determine a critical threshold for predicting clinical endometrisit each day of sampling. The higher area under the curve (AUC) values related to each metabolite and disease were determined as the most predictive critical threshold for identication of disease. Sensitivity, specificity, and likelihood ratios (LRs) were also calculated.

\section{Results and discussion}

While 68 animals were enrolled the study, only 60 were used for analysis at the end of the study period. Eight animals were excluded from the study (two animals were culled by farm personel due to locomotor sytem disorders during the first week of lactation, one animal had a c-section, three animals had retention of fetal membranes, and two animals were excluded due to incomplete data collection problems). The average minimum and maximum THIs during the study period were $59.91( \pm 8.23)$ and $61.71( \pm 7.44)$ respectively. None of the cows experienced a Max THI greater than 72. The number of parities were not statistically significant in healthy cows $(3.1 \pm 1.2)$ and the cows with clinical endometritis $(2.9 \pm 1.4)$. Body temperatures measured and recorded daily during the first 10 DIM were similar among the two groups of cows (38.73 $\pm 0.02,38.62 \pm 0.06$ healthy and cows that developed clinical endometritis, respectively). Although, the average milk production 30-day milk yield was frequently lower $(29 \pm 8.81-28 \pm 8.73$ liter per day for healthy cows than in cows that developed endometritis, respectively), there was no significant difference among the two groups. There are different claims about the effect of hypocalcemia on milk yield. Although Østergaard and Larsen (31) did not observe any changes in milk yield, Jawor et al. (18) observed the positive role of hypocalcemia on milk yield of dairy cows during the lactation. However, the mechanism underlying such results has not been explained yet.

Although the sample size was low, the two groups were carefully balanced according to their uterine health so that differences in milk yield, BCS, some blood metabolites and ions concentrations could be 


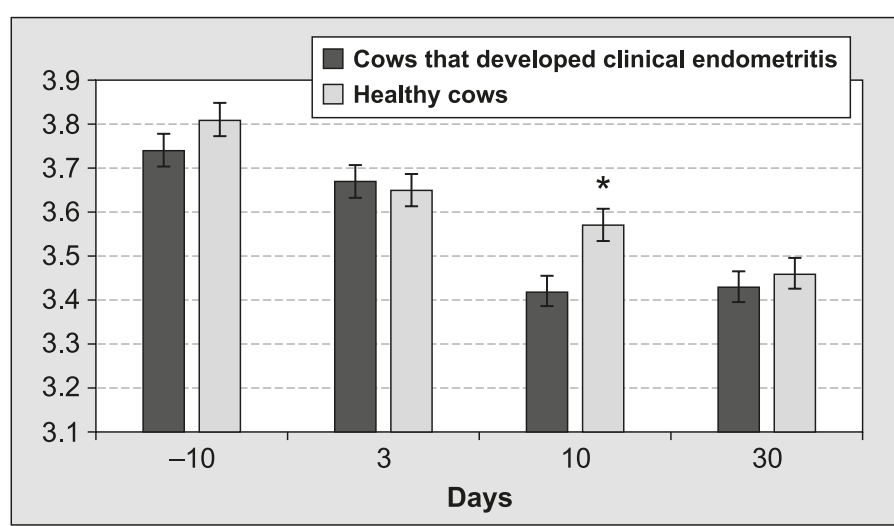

Fig. 1. Body condition score changes among groups during the study period

observed. A uterine infection that is restricted to the endometrium layer is called clinical endometritis and characterized by purulent or mucopurulent discharge after 20 DIM, or mucopurulent discharge after 26 DIM (22). It is not clear that a negative energy balance had a role on the severity of these changes (14). But macromineral homeostasis during the transition period may have influenced the metabolic and hormonal adaptations (27). A reduced dry matter intake and immunosuppression in postpartum period are associated with clinical endometritis $(16,18)$.

Over time, BCS and the concentrations of Ca, NEFA, $\mathrm{BHB}$, glucose, cholesterol, and $\mathrm{P}$ changed in both groups $(\mathrm{P}<0.001)$. There was an interaction noted in the groups over time for BCS, NEFA, BHB, glucose, and $\mathrm{Ca}$ concentration. There were not any statistical differences in BCS during the study period except at 10 DIM among the two groups as shown in Figure 1. BCS were higher at 10 DIM in healthy cows when compared to cows that developed clinical endometritis $(\mathrm{P}<0.05)$. Although, Sheehy et al. (36) reported that $\mathrm{BCS}$ loss during prepartum period negatively affects the calcium status of dairy cows, all cows that examined peripartum period had a similar BCS. Thus, decreased $\mathrm{Ca}$ concentration at 3 DIM were not related with peripartal BCS status in present study.

Mean $\mathrm{Ca}$ levels during the study period are shown in Figure 2. There was a significant difference in mean calcium levels between the groups on 3 DIM. Cows that have clinical endometritis on $30 \pm 4$ DIM previously suffered from subclinical hypocalcemia at 3 DIM. Although NEFA levels did not show any significant difference on prepartum $10( \pm 4)$, and 3, $30( \pm 4)$ DIM (Fig. 3), NEFA concentrations were greater in cows that subsequently developed clinical endometritis at 10 DIM. BHB levels were higher at 10 and $30( \pm 4)$ DIM in the same group as shown in Fig. $4(\mathrm{P}<0.05)$. Although there was a significant difference on BHB levels, concentrations were in the normal range. Whereas $\mathrm{Ca}$ is an essential ion for myometrial smooth muscle cell contractility and all digestive system motility (2), the exact effect of calcium imbalance during the postpartum period on the

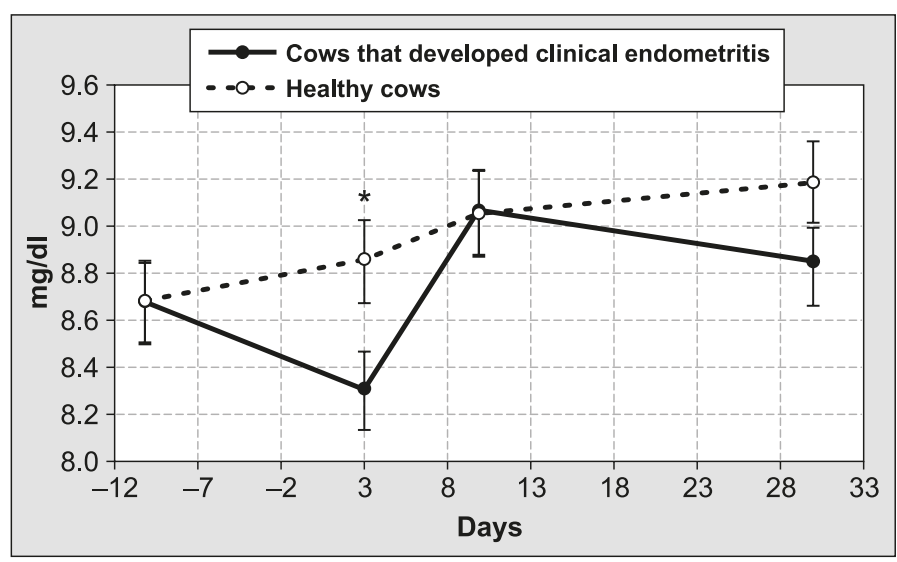

Fig. 2. Serum Ca concentrations in healthy cows and cows with clinical endometritits during the study period

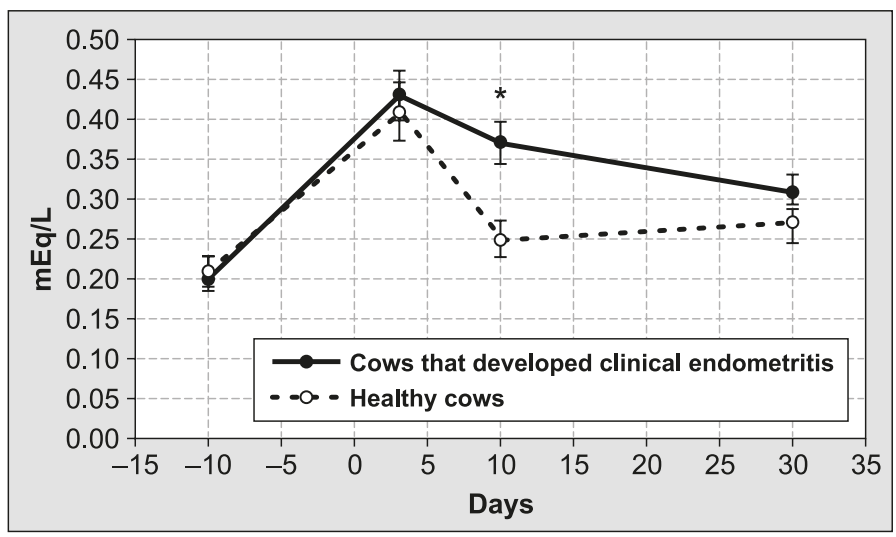

Fig. 3. Mean serum NEFA concentrations during the study period in cows with or without clinical endometritits (NEFA: non-esteried fatty acid)

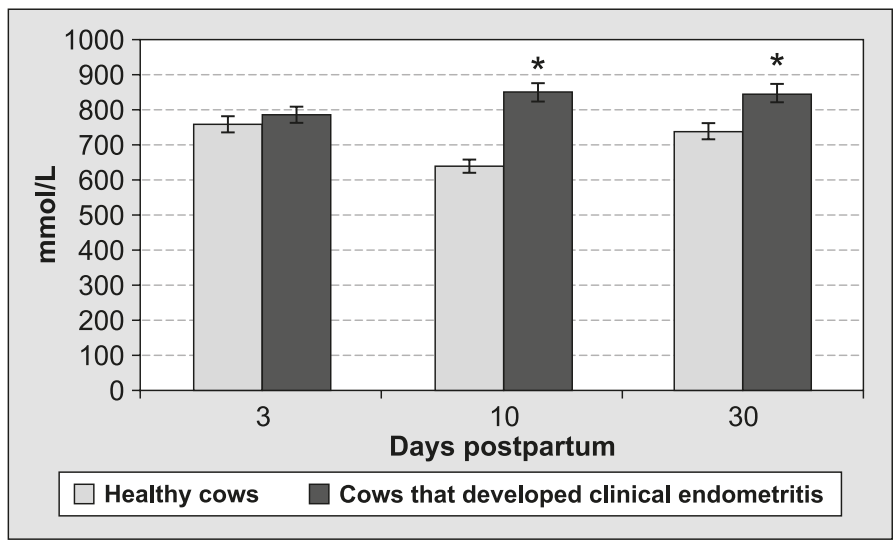

Fig. 4. Serum BHB concentrations during the postpartum period in healthy cows and cows that developed clinical endometritits (BHB: beta hydroxybutiric acid)

occurrence of endometritis is not well understood yet. In the present study, the subclinical hypocalcemia at 3 DIM might provide conditions under which the occurrence of clinical endometritis at $30 \pm 4$ DIM, and the serum NEFA and BHB concentrations was greater at 10 DIM in cows that subsequently developed clinical endometritis. But NEFA and BHB concentrations were in the normal range. This situation might be explained as the adipocytes stimulated calcium sensing receptor agonists had decreased basal lipolysis and, as 
Tab. 2. Mean serum glucose, phosphorus and cholesterol concentrations among groups during the study period

\begin{tabular}{|c|c|c|c|c|c|c|c|}
\hline \multirow{2}{*}{ Parameters } & \multicolumn{4}{|c|}{ Days } & \multicolumn{3}{|c|}{$P$ value } \\
\hline & $-10 \pm 4$ Antepartum & 3 Postpartum & 10 Postpartum & $30 \pm 4$ Postpartum & Group & Time & Group $\times$ Time \\
\hline \multicolumn{8}{|l|}{ Glucose (mg/dL) } \\
\hline Cows with endometritis & $67.81 \pm 1.67^{a}$ & $61.88 \pm 3.66^{A, ~ a b}$ & $53.47 \pm 2.12^{\mathrm{b}}$ & $56.87 \pm 1.99^{b}$ & 0.085 & $<0.001$ & 0.029 \\
\hline Healthy cows & $65.28 \pm 1.21^{a}$ & $51.87 \pm 2.76^{\mathrm{B}, \mathrm{b}}$ & $50.93 \pm 2.14^{b}$ & $57.78 \pm 2.35^{b}$ & & & \\
\hline \multicolumn{8}{|l|}{ Phosphorus (mg/dL) } \\
\hline Cows with endometritis & $6.24 \pm 0.14^{b}$ & $5.50 \pm 0.28^{b}$ & $6.07 \pm 0.20^{b}$ & $7.51 \pm 0.56^{\mathrm{a}}$ & 0.266 & 0.012 & 0.106 \\
\hline Healthy cows & $6.29 \pm 0.17$ & $6.00 \pm 0.56$ & $5.60 \pm 0.32$ & $6.31 \pm 0.26$ & & & \\
\hline \multicolumn{8}{|l|}{ Cholesterol (mg/dL) } \\
\hline Cows with endometritis & $93.38 \pm 3.45^{b}$ & $70.23 \pm 2.91^{c}$ & $82.00 \pm 4.95^{\mathrm{bc}}$ & $113.70 \pm 6.23^{a}$ & 0.529 & $<0.001$ & 0.249 \\
\hline Healthy cows & $86.29 \pm 2.52^{b}$ & $73.16 \pm 3.58^{c}$ & $89.77 \pm 5.47^{b}$ & $118.38 \pm 5.11^{a}$ & & & \\
\hline
\end{tabular}

Explanations: Means within a row (a-c) and column (A-B) with differ superscript letters differ significantly $(\mathrm{P}<0.05)$

a result, lipolysis may increase with Ca depletion (8). As calcium is part of another mechanism, it is a second messenger for energy metabolism in hepatocytes. Calcium directly impacts the tricarboxylic acid cycle. Even more so, under the effect of inadequate calcium levels in the body at 3 DIM, carbohydrate metabolism via tricarboxylic acid cycle was altered at 10 DIM and the result was more severe energy balance (6).

Glucose levels did not show any significant difference on $10( \pm 4)$ antepartum, 10 days postpartum, and $30( \pm 4)$ days postpartum. As illustrated in Table 2, peripartum blood glucose concentrations were lower at 3 DIM in healthy cows $(\mathrm{P}<0.05)$. Hypocalcemia impairs insulin release in dairy cows (26). Thus, subclinical hypocalcemia impairs insulin secretion from the pancreas, which increases glucose concentration in blood by reducing the uptake of glucose by peripheral tissues (15). Although insulin levels were not measured, the present findings support the claim that cows suffering from subclinical hypocalcemia have higher glucose levels at 3 DIM. Hypocalcemia has a direct effect on immunosuppression that occurs via depleting intracellular $\mathrm{Ca}$ stores in peripheral blood mononuclear cells (24). Martinez et al. (26) reported that subclinical hypocalcemia impaired the function of immune cells and this may increase the risk of developing endometritis in cows, which is consistent with the results of this study. In agreement with Bicalho et al. (30) glucose concentration was lower in healthy cows. Lower glucose concentration might be related with udder production. Mammary gland use 50\% to $85 \%$ of blood glucose consumption (30) and healthy cows that produce more milk (however, statistically not significant) will present lower glucose concentration.

There were no groups by time interactions noted in levels of cholesterol and phosphorus concentrations, as shown in Table 2. Cholesterol has been identified as a precursor of ovarian steroids and decreasing total cholesterol concentration at early lactation might impair steroidogenesis and delay resumption of ovarian functioning (38). Although the results in this study showed no statistical differences, cholesterol levels were relatively higher in healthy cows than cows that subsequently developed clinical endometritis. This condition might affect the ovarian activity in the present study.

The $\mathrm{P}$ concentration was negatively correlated with NEFA $(r=-0.389 ; \mathrm{P}<0.05)$ and strongly correlated with Ca levels $(\mathrm{r}=0.530 ; \mathrm{P}<0.005)$ on $10 \pm 4$ days before the expected parturition in cows that subsequently developed endometritis. Blood glucose concentrations on the same day were negatively correlated with blood NEFA concentrations $(\mathrm{r}=-0.531 ; \mathrm{P}<0.005)$. Body condition scores correlated with blood $\mathrm{Ca}$ concentration at 3 and 10 days postpartum $(\mathrm{r}=0.406 ; \mathrm{P}<0.05$; $\mathrm{r}=0.532 ; \mathrm{P}<0.005$ respectively), and blood glucose concentrations were strongly correlated with $\mathrm{P}(\mathrm{r}=514$; $\mathrm{P}<0.005)$ on 3 DIM. Blood NEFA concentrations were negatively correlated with cholesterol concentration $(\mathrm{r}=-0.432, \mathrm{P}<0.05)$ at 10 DIM. In addition, BHB concentrations were negatively correlated with blood glucose levels $(\mathrm{r}=-0.669 ; \mathrm{P}<0.05)$. Blood total $\mathrm{Ca}$ levels were positively correlated with cholesterol $(\mathrm{r}=$ $0.515 ; \mathrm{P}<0.005)$ and glucose $(\mathrm{r}=0.648 ; \mathrm{P}<0.0001)$ levels on $30( \pm 4)$ DIM. The evaluation of the correlation between some blood parameters and BCS in healthy cows showed that total $\mathrm{Ca}$ concentration correlated with $\mathrm{P}$ concentrations $(\mathrm{r}=0.579 ; \mathrm{P}<0.001)$ at $10( \pm 4)$ days prior to expected parturition. Glucose concentrations showed negative correlation with NEFA concentrations $(\mathrm{r}=-0.476 ; \mathrm{P}<0.05)$ on $10( \pm 4)$ days prepartum. NEFA concentrations strongly correlated with $\mathrm{BHB}$ concentrations at 3,10 days postpartum $(\mathrm{r}=0.847 ; \mathrm{P}<0.0001 ; \mathrm{r}=0.821 ; \mathrm{P}<0.0001$ respectively). BCS were correlated with NEFA concentration $(\mathrm{r}=0.448 ; \mathrm{P}<0.05)$ at $30 \pm 4$ DIM. During the same day, BHB concentrations were negatively correlated with glucose concentration $(\mathrm{r}=-0.541 ; \mathrm{P}<0.05)$.

ROC analysis was perfomed to determine critical thresholds (i.e., highest sensivity and specifity) for glucose, NEFA, BHB, Ca and BCS in order to predict the subsequently developed clinical endometritis. The results of ROC curve analysis for determination of clinical thresholds, specifity, sensivity, AUC, LR 
Tab. 3. Receiver operating characteristic (ROC) curve analysis for the determination of critical thresholds for NEFA, BHB, calcium and glucose as predictors of clinical endometritis in Brown Swiss dairy cows. The results of ROC curve analysis of critical NEFA, BHB, calcium and glucose thresholds for prediction of clinical endometritis tabulated and ranked by their respective AUC. Data about the levels on NEFA, BHB, calcium and glucose showing sensivity, specifity, and LR+ are also provided

\begin{tabular}{|c|c|c|c|c|c|c|c|c|c|}
\hline Metabolite & Days $^{a}$ & Threshold $^{\mathrm{b}}$ & $\mathrm{Se}^{\mathrm{c}}$ & \%95 Cl for Se & $S p^{d}$ & $\% 95 \mathrm{Cl}$ for $\mathrm{Sp}$ & $\mathbf{L R} \mathbf{t}^{\mathrm{e}}$ & $A U C^{\prime}$ & p \\
\hline NEFA (mEq/L) & 10 & 0.25 & 70 & $50.6-85.2$ & 74.2 & $55.4-88.1$ & 2.71 & 0.741 & $<0.001$ \\
\hline BHBA $(\mu \mathrm{mol} / \mathrm{L})$ & 10 & 760.69 & 61.5 & $31.6-86.0$ & 78.6 & 49.2-95.1 & 2.87 & 0.626 & 0.247 \\
\hline Calcium (mg/dl) & 3 & 9 & 80 & $61.4-92.2$ & 45.2 & $27.3-64.0$ & 1.46 & 0.627 & 0.076 \\
\hline Glucose (mg/dl) & 3 & 69.6 & 23.3 & $10.0-42.3$ & 90.3 & $74.2-97.8$ & 2.41 & 0.545 & 0.543 \\
\hline
\end{tabular}

Explanations: $\mathrm{a}$ - days postpartum; b - highest combined sensivity and specifity; c - Se: epidemiologic sensivity; $\mathrm{d}$ - Sp: epidemiologic specifity; e - positive likelihood ratio; f - area under the curve

and $P$ values are presented in Table 3. The LRs were determined based on critical thresholds calculated by univariable ROC analysis. To illusturate, LR positive $(\mathrm{LR}+)$ reflects the likelihood that a positive test result (i.e., value equal or under the threshold) could come from an animal that subsequently developed clinical endometritis in comparison to healthy animal. Moreover, ROC curves for critical threshold for glucoe, NEFA, BHB and Ca predicting the endometritis are shown in Figure 5. For predicting the endometritis, the ROC curve for NEFA presented a higher AUC of 0.741 , when compared with those of BHB (0.626), glucose (0.520) and $\mathrm{Ca}(0.518)$. When compared with

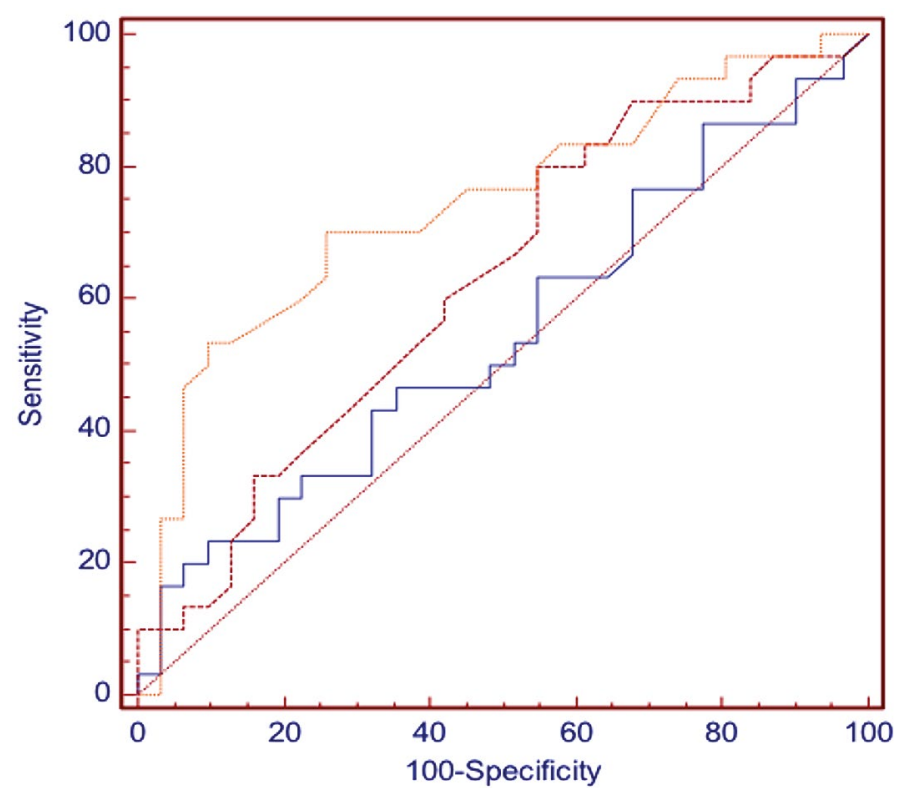

Fig. 5. Display of ROC curves that determined the clinical threshold for concentration of NEFA at 10 days after parturition ( $\geq 0.25 \mathrm{mEq} / \mathrm{L}$; doded line). Ca ( $9 \mathrm{mg} / \mathrm{dl}$, dashed line) and glucose $(\geq 69.9 \mathrm{mg} / \mathrm{dl}$, solid line) at 3 days postpartum predicting clinical endometritis. Pairwise comparison of AUC values of ROC curves assigned that the difference between AUC for NEFA and Ca (0.115; SE: 0.086;\% 95 CI, -0.054 to $0.283, P=0.183)$; as well as the difference between glucose and Ca (0.082; SE: $0.095 ; \% 95$ CI, -0.104 to $0.267, \mathrm{P}=0.388)$; and the difference between glucose and NEFA $(0.196 ; \mathrm{SE}: 0.085 ; \%$ $95 \mathrm{CI}, 0.029$ to $0.363, \mathrm{P}=\mathbf{0 . 0 2 1})$. The diagonal line represents the specifity and sensivity level at which the test informative (ROC, receiver operating characteristic; AUC, area under the curve; NEFA, non-esterifed fatty acid; Ca, calcium; SE, standart error; $\mathrm{CI}$, confidence interval) other metabolites, NEFA concentration at 10 days postpartum was the best predictor for endometritis diagnosis. Contrary to Burke et al. (4) and Dubuc et al. (10) the results suggest that NEFA concentration is a significant risk factor for clinical endometritis according to ROC analysis. The high NEFA increase proinflamatory response as well as cytokine production (9). Thus, overproduction of proinflamatory cytokines might suppress uterine immune response and have a role in the occurrence of clinical endometritis in the early postpartum period.

Approximately $64.5 \%$, or 20 of 31 cows in the healthy group were cyclic while $58.6 \%$, or 17 of 29 cows were cyclic in cows that developed clinical endometritis at $30( \pm 4)$ DIM examination. The relationship between resumption of ovarian activity and subclinical hypocalcemia were evaluated, it was reported that cows with subclinical hypocalcemia had delayed resumption of ovarian activity (22). As previously explained subsequent progesterone concentration was greater in normocalcemic cows the first 3 days after parturition in comparision to hypocalcemic cows. Additionally, resumption of ovarian activity was earlier in normocalcemic cows (5). The mechanism related to the delay of resumption in ovarian activity and subclinical hypocalcemia might be impaired due to blood flow to ovaries (20) in addition to the other metabolic disturbances. Under the effect of endometritis, delayed resumption of ovarian activity function has been observed in dairy cows $(21,30)$.

In conclusion, this study shows that NEFA concentration is the risk factor for clinical endometritis, and not $\mathrm{Ca}, \mathrm{BHB}$ and glucose. Subclinical hypocalcemia in the peripartum period might affect the occurrence of clinical endometritis indirectly by changing some blood metabolite concentrations and delaying the resumption of ovarian activities in dairy cows.

\section{References}

1. Aguilar I., Misztal I., Tsuruta S.: Genetic trends of milk yield under heat stress for US Holsteins. J. Dairy Sci. 2010, 93, 1754-1758.

2. Allen M. S.: Effects of diet on short-term regulation of feed intake by lactating dairy cattle. J. Dairy Sci. 2000, 83, 1598-1624.

3. Bicalho M. L. S., Marques E. C., Gilbert R. O., Bicalho R. C.: The association of plasma glucose, BHBA, and NEFA with postpartum uterine diseases, fertility, and milk production of Holstein dairy cows. Theriogenology 2017 , $88,270-282$ 
4. Burke C. R., Meier S., McDougall S., Compton C., Mitchell M., Roche, J. R.: Relationships between endometritis and metabolic state during the transition period in pasture-grazed dairy cows. J. Dairy Sci. 2010, 93, 5363-5373.

5. Caixeta L. S., Ospina P. A., Capel M. B., Nydam D. V.: The association of subclinical hypocalcemia, negative energy balance and disease with bodyweight change during the first 30 days post-partum in dairy cows milked with automatic milking systems. Vet. J. 2015, 204, 150-156.

6. Chamberlin W. G., Middleton J. R., Spain J. N., Johnson G. C., Ellersieck M. R., Pithua P.: Subclinical hypocalcemia, plasma biochemical parameters, lipid metabolism, postpartum disease, and fertility in postparturient dairy cows. J. Dairy Sci. 2013, 96, 7001-7013.

7. Chapinal N., Carson M. E., LeBlanc S. J., Leslie K. E., Godden S., Capel M., Duffield T. F.: The association of serum metabolites in the transition period with milk production and early-lactation reproductive performance. J. Dairy Sci. 2012, 95, 1301-1309.

8. Cifuentes M., Rojas C. V.: Antilipolytic effect of calcium-sensing receptor in human adipocytes. Mol. Cell Biochem. 2008, 319, 17-21.

9. De Loera-Rodriguez C. O., Delgado-Rizo V., Alvarado-Navarro A., AgrazCibrian J. M., Segura-Ortega J. E., Fafutis-Morris M.: Over-expression of TLR4-CD14, pro-inflammatory cytokines, metabolic markers and NEFAs in obese non-diabetic Mexicans. Eur. J. Inflamm. 2014, 11, 1-7.

10. Dubuc J., Duffield T. F., Leslie K. E., Walton J. S., LeBlanc S. J.: Risk factors for postpartum uterine diseases in dairy cows. J. Dairy Sci. 2010, 93, 5764-5771 .

11. Duffield T. F., Lissemore K. D., McBride B. W., Leslie K. E.: Impact of hyperketonemia in early lactation dairy cows on health and production. J. Dairy Sci. 2009, 92, 571-580.

12.Ferguson J. D., Galligan D. T., Thomsen N.: Principal descriptors of body condition score in Holstein cows. J. Dairy Sci. 1994, 77, 2695-2703.

13. Földi J., Kulcsar M., Pecsi A., Huyghe B., De Sa C., Lohuis J. A. C. M., Huszenicza $G$. Y: Bacterial complications of postpartum uterine involution in cattle. Anim. Reprod. Sci. 2006, 96, 265-281.

14. Grummer R. R., Mashek D. G., Hayirli A.: Dry matter intake and energy balance in the transition period. Vet. Clin. North Am. Food Anim. Prac. 2004, $20,447-470$

15. Hammon D., Evjen I. M., Dhiman T. R., Goff J. P., Walters J. L.: Neutrophil function and energy status in Holstein cows with uterine health disorders. Vet. Immunol. Immunopathol. 2006, 113, 21-29.

16. Horst R. L., Goff J. P., Reinhardt T. A.: Calcium and vitamin D metabolism in the dairy cow. J. Dairy Sci. 1994, 77, 1936-1951.

17. Huzzey J. M., Veira D. M., Weary D. M., Von Keyserlingk M. A. G.: Prepartum behavior and dry matter intake identify dairy cows at risk for metritis. J. Dairy Sci. 2007, 90, 3220-3233.

18. Jawor P. E., Huzzey J. M., LeBlanc S. J., von Keyserlingk M. A. G.: Associations of subclinical hypocalcemia at calving with milk yield, and feeding, drinking, and standing behaviors around parturition in Holstein cows. J. Dairy Sci. 2012, 95, 1240-1248.

19. Jonsson N. N., Daniel R. C. W.: Effects of hypocalcaemia on blood flow to the ovaries of the sheep. J. Vet. Med. A 1997, 44, 281-287.

20. Kadivar A., Ahmadi M. R., Vatankhah M.: Associations of prepartum body condition score with occurrence of clinical endometritis and resumption of postpartum ovarian activity in dairy cattle. Trop. Anim. Health Pro. 2014, 46, 121-126.

21. Kamgarpour R., Daniel R. C. W., Fenwick D. C., McGuigan K., Murphy G.: Post partum Subclinical Hypocalcaemia and Effects on Ovarian Function and Uterine Involution in a Dairy Herd. Vet. J. 1999, 158, 59-67.

22. Khan M. J., Hosseini A., Burrell S., Rocco S. M., McNamara J. P., Loor J. J.: Change in subcutaneous adipose tissue metabolism and gene network expression during the transition period in dairy cows, including differences due to sire genetic merit. J. Dairy Sci. 2013, 96, 2171-2182.

23. Kimura K., Reinhardt T. A., Goff J. P.: Parturition and hypocalcemia blunts calcium signals in immune cells of dairy cattle. J. Dairy Sci. 2006, 89, 2588-2595 .

24. LeBlanc S. J., Leslie K. E., Duffield T. F.: Metabolic predictors of displaced abomasum in dairy cattle. J. Dairy Sci. 2005, 88, 159-170.

25. Littledike E. T., Witzel D. A., Whipp S. C.: Insulin: Evidence for inhibition of release in spontaneous hypocalcemia. Proc. Soc. Exp. Biol. Med. 1968, 129, 135-139.

26. Martinez N., Risco C. A., Lima F. S., Bisinotto R. S., Greco L. F., Ribeiro E. S., Santos J. E. P.: Evaluation of peripartal calcium status, energetic profile, and neutrophil function in dairy cows at low or high risk of developing uterine disease. J. Dairy Sci. 2012, 95, 7158-7172.

27. McArt J. A. A., Nydam D. V., Oetzel G. R.: Epidemiology of subclinical ketosis in early lactation dairy cattle. J. Dairy Sci. 2012, 95, 5056-5066.

28. McLaren C. J., Lissemore K. D., Duffield T. F., Leslie K. E., Kelton D. F., Grexton B.: The relationship between herd level disease incidence and a return over feed index in Ontario dairy herds. Can. Vet. J. 2006, 47, 767.
29. Nakao T., Moriyoshi M., Kawata K.: The effect of postpartum ovarian dysfunction and endometritis on subsequent reproductive performance in high and medium producing dairy cows. Theriogenology 1992, 37, 341-349.

30. Ospina P. A., Nydam D. V., Stokol T., Overton T. R.: Association between the proportion of sampled transition cows with increased nonesterified fatty acids and $\beta$-hydroxybutyrate and disease incidence, pregnancy rate, and milk production at the herd level. J. Dairy Sci. 2010, 93, 3595-3601.

31. Østergaard S., Larsen T: Associations between blood calcium status at calving and milk yield in dairy cows. J. Dairy Sci. 2000, 83, 2438-2440.

32. Rabiee A. R., Lean I. J.: Uptake of glucose and cholesterol by the ovary of sheep and cattle and the influence of arterial LH concentrations. Anim. Reprod. Sci. 2010, 64, 199-209.

33. Ramberg C. F. Jr, Johnson E. K., Fargo R. D., Kronfeld D. S.: Calcium homeostasis in cows, with special reference to parturient hypocalcemia Am. J. Physiol. Regul. Integr. Comp. Physiol. 1984, 246, 698-704.

34. Ramberg C. F. Jr, Mayer G. P., Kronfeld D. S., Phang J. M., Berman M. Calcium kinetics in cows during late pregnancy, parturition, and early lactation. Am. J. Physiol. 1970, 219, 1166-1177.

35. Seifi H. A., LeBlanc S. J., Leslie K. E., Duffield T. F.: Metabolic predictors of post-partum disease and culling risk in dairy cattle. Vet. J. 2011, 188, 216-220.

36. Sheehy M. R., Fahey A. G., Aungier S. P. M., Carter F., Crowe M. A., Mulligan $F$. $J$ : A comparison of serum metabolic and production profiles of dairy cows that maintained or lost body condition 15 days before calving. J. Dairy Sci. 2017, 100, 536-547.

37. Sheldon I. M., Lewis G. S., LeBlanc S., Gilbert R. O.: Defining postpartum uterine disease in cattle. Theriogenology 2006, 65, 1516-1530.

38. Staples C. R., Burke J. M., Thatcher W. W.: Influence of supplemental fats on reproductive tissues and performance of lactating cows. J. Dairy Sci. 1998, 81, 856-871.

39. Walsh R. B., Kelton D. F., Duffield T. F., Leslie K. E., Walton J. S., LeBlanc $S$. $J$. : Prevalence and risk factors for postpartum anovulatory condition in dairy cows. J. Dairy Sci. 2007, 90, 315-324.

40. Williams E. J., Fischer D. P., Pfeiffer D. U., England G. C., Noakes D. E., Dobson H., Sheldon I. M.: Clinical evaluation of postpartum vaginal mucus reflects uterine bacterial infection and the immune response in cattle. Theriogenology 2005, 63, 102-117.

41. Zhao F. Q., Keating A. F.: Expression and regulation of glucose transporters in the bovine mammary gland. J. Dairy Sci. 2007, 90, 76-86.

Corresponding author: Dr. Murat Onur Yazlik, Department of Obstetrics and Gyneacology, Faculty of Veterinary Medicine, Ankara University, Ankara, 06110, Turkey 